\section{p63 is the molecular switch for initiation of an epithelial stratification program}

\author{
Maranke I. Koster, ${ }^{1}$ Soeun Kim, ${ }^{2}$ Alea A. Mills, ${ }^{4}$ \\ Francesco J. DeMayo, ${ }^{1,2}$ and Dennis R. Roop ${ }^{1,2,3,5}$ \\ ${ }^{1}$ Program in Developmental Biology and ${ }^{2}$ Departments of \\ Molecular and Cellular Biology and ${ }^{3}$ Dermatology, Baylor \\ College of Medicine, Houston, Texas 77030, USA; ${ }^{4}$ Cold \\ Spring Harbor Laboratory, Cold Spring Harbor, New York \\ 11724, USA
}

Development of stratified epithelia, such as the epidermis, requires p63 expression. The p63 gene encodes isoforms that contain (TA) or lack $(\Delta N)$ a transactivation domain. We demonstrate that TAp63 isoforms are the first to be expressed during embryogenesis and are required for initiation of epithelial stratification. In addition, TAp63 isoforms inhibit terminal differentiation, suggesting that TAp63 isoforms must be counterbalanced by $\Delta \mathrm{Np} 63$ isoforms to allow cells to respond to signals required for maturation of embryonic epidermis. Our data demonstrate that $p 63$ plays a dual role: initiating epithelial stratification during development and maintaining proliferative potential of basal keratinocytes in mature epidermis.

Received October 28, 2003; revised version accepted December 1, 2003.

Development of the epidermis requires a series of coordinated events, which regulate proliferation and differentiation of keratinocytes. Although recent discoveries have highlighted a number of genes required for terminal differentiation of keratinocytes (Hu et al. 1999; Takeda et al 1999; Rangarajan et al. 2001; Nickoloff et al. 2002; Nicolas et al. 2003), a question that remains is how the single-layered surface ectoderm commits to initiate stratification during embryogenesis. A candidate gene involved in this process is the transcription factor p63. p63 is expressed in the surface ectoderm prior to stratification and continues to be expressed during embryonic development. As the epidermis matures, p63 expression becomes restricted to the basal layer. In adult tissues, p63 is expressed in stratified epithelia, whereas its expression is absent from single-layered epithelia (Yang et al. 1998). These expression data suggest a role for p63 in the development and maintenance of stratified epithelia, such as the epidermis. In support of this hypothesis, investigators found that mice lacking $p 63$ display a fundamental defect in epithelial lineage development and fail to develop stratified epithelia and epithelial appendages, such as teeth, hair follicles and mammary glands (Mills

[Keywords: p63; stratified epithelia; molecular switch; embryogenesis; terminal differentiation; proliferative potential] ${ }^{5}$ Corresponding author.

E-MAIL roopd@bcm.tmc.edu; FAX (713) 798-3800.

Article published online ahead of print. Article and publication date are at http://www.genesdev.org/cgi/doi/10.1101/gad.1165104. et al. 1999; Yang et al. 1999). The surface epithelium of p $63^{-/-}$newborn mice consists of a single cell layer that fails to express epidermal differentiation markers, including keratins K5 and K14 (Mills et al. 1999; Yang et al. 1999|. The lack of stratification and the consequent absence of barrier formation in $p 63^{-/-}$mice results in dehydration and death within hours after birth. This fundamental defect in stratified epithelial lineage development displayed by $p 63^{-/-}$mice has led to two hypotheses concerning the potential role of $p 63$ in epidermal development. It has been proposed that $p 63$ may play a pivotal role in maintaining the stem cell population in an already committed stratified epithelium (Yang et al. 1999; Pellegrini et al. 2001). Alternatively, p63 may play a critical role in the commitment to stratified epithelial lineages (Mills et al. 1999).

In an attempt to distinguish between these hypotheses, we further investigated the molecular role of $p 63$ in development of the embryonic epidermis and maintenance of the mature epidermis. p63 is expressed in at least six isoforms (Yang et al. 1998). The use of alternative promoters and transcription start sites gives rise to two classes of $p 63$ transcripts: those encoding proteins with an amino terminal transactivation domain (TA isoforms) and those encoding proteins lacking this domain ( $\Delta \mathrm{N}$ isoforms). In addition, alternative splicing gives rise to three different carboxyl termini designated $\alpha, \beta$, and $\gamma$. In vitro data suggest that $\Delta \mathrm{Np} 63$ isoforms have a dominant-negative function toward TAp63 isoforms (Yang et al. 1998 ); however, $\Delta \mathrm{Np} 63$ isoforms were also shown to be able to transactivate target gene expression (Dohn et al. 2001; King et al. 2003; Wu et al. 2003), possibly because of the presence of a second transactivation domain within $\Delta$ Np63 isoforms (Ghioni et al. 2002). It has been reported that the predominant p63 isoform expressed in mature epidermis is $\Delta \mathrm{Np} 63 \alpha$ (Yang et al. 1998; Liefer et al. 2000).

We now demonstrate that TAp63 isoforms are the first p63 isoforms expressed during embryogenesis and that they are required for initiation of epithelial stratification. Furthermore, ectopic expression of a TAp63 isoform in a simple epithelium in vivo resulted in the induction of squamous metaplasia, confirming the role of p63 as a master molecular switch. We also show that TAp63 isoforms inhibit terminal differentiation, suggesting that TAp63 isoforms must be counterbalanced by $\Delta$ Np63 isoforms to allow cells to respond to signals required for maturation of embryonic epidermis. Our data are consistent with $p 63$ playing a dual role: initiating epithelial stratification during development and maintaining proliferative potential of basal keratinocytes in mature epidermis.

\section{Results and Discussion}

From the expression pattern of $p 63$ and the phenotype of $p 63^{-/-}$mice, we hypothesized that $\mathrm{p} 63$ is required for the induction of an epithelial stratification program. In support of this hypothesis, we have isolated $p 63^{-/-}$cells from the surface epithelium of E18.5 $p 63^{-/-}$mice. Like $p 63^{-/-}$skin, $p 63^{-/-}$cells failed to express K5 and K14 (Fig. 1), differentiation markers that are expressed in epithelia that have committed to initiate a stratification program (Byrne et al. 1994), as well as terminal differentiation markers $\mathrm{K} 1$ and loricrin (data not shown). Instead, $p 63^{-/-}$ 


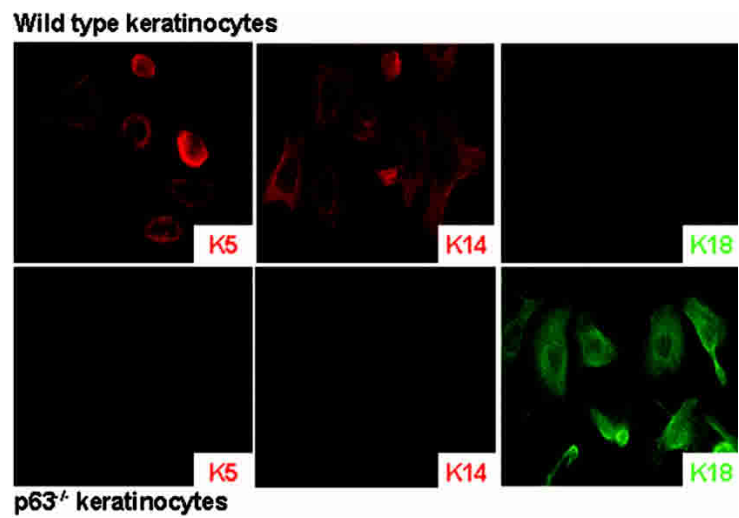

Figure 1. Primary $\mathrm{p} 63^{-/-}$surface epithelial cells are blocked in their commitment to a stratified epithelial lineage. Differentiation markers $\mathrm{K} 5$ and $\mathrm{K} 14$, which are expressed in epithelia that have committed to a stratification program, are not expressed in primary $\mathrm{p} 63^{-1-}$ cells. These cells do, however, express K18, a marker for singlelayered epithelia.

cells expressed K18, which is normally synthesized in the surface ectoderm prior to stratification and in adult single-layered epithelia (Jackson et al. 1981; Moll et al. 1982). These data demonstrate that without $p 63$, surface epithelial cells are intrinsically blocked in their commitment to become a keratinocyte.

To study the role of $p 63$ during epidermal morphogenesis, we determined the expression profiles of TA- and $\Delta$ Np63 isoforms during embryonic development. We found that $\Delta \mathrm{Np} 63$ isoforms were first expressed at E9.5, after the developing epidermis has committed to stratification, but prior to terminal differentiation (Fig. 2a; Byrne et al. 1994). However, TAp63 isoforms were detected as early as E7.5, prior to the commitment to stratification. In addition, we observed nuclear p63 staining in every cell in the surface ectoderm of E8.5 embryos, suggesting that expression of TAp63 isoforms is required in this tissue (Fig. 2b,c). Based on these data, we hypothesized that TAp63 isoforms may be required for the initiation of an epithelial stratification program. To test this hypothesis, we transfected expression constructs encoding TAp $63 \alpha, \mathrm{TAp} 63 \gamma, \Delta \mathrm{Np} 63 \alpha$, and $\Delta \mathrm{Np} 63 \gamma$ into cells that do not express p63 or K14 (Ptk2 cells, HR9 cells, and F9 cells) and analyzed the induction of K14 expression. As expected from their expression patterns, we found that only TAp63 isoforms were able to induce K14 expression, whereas $\Delta \mathrm{Np} 63$ isoforms did not affect K14 expression (Fig. 3a). To determine whether TAp63 isoforms could initiate a stratification program in vivo, we ectopically expressed TAp63 $\alpha$ in single-layered lung epithelia by using "gene-switch" mice (Wang et al. 1997, 1999; Cao et al. 2002). The regulator of the gene-switch system (Glp65) is activated by progesterone antagonists such as RU486 and was placed under control of the surfactant protein C promoter (SP-C.Glp65), as previously described (Zhao et al. 2001). The SP-C promoter targets transgene expression to the cuboidal, surfactant-secreting type II alveolar cells and to the distal Clara cells, which line the bronchioles of the lung (Wikenheiser and Whitsell 1997). Neither of these cell types normally expresses p63 (Yang et al. 1998) or markers of stratified epithelial differentiation, K5 and K14 (Fig. 3e,f; Kasper et al. 1993). Adult bigenic SP-C.Glp65/TAp63 $\alpha$ mice, SPC.Glp $65 / \Delta \mathrm{Np} 63 \alpha$ mice, and control mice were treated with $500 \mu \mathrm{g} / \mathrm{kg}$ RU486 once daily for $7 \mathrm{~d}$, which resulted in induction of transgene expression (Fig. 3b). Lung biopsy specimens demonstrated that ectopic TAp63 $\alpha$ expression resulted in the induction of K5 and K14 expression in type II alveolar cells (data not shown). Furthermore, squamous metaplastic lesions developed in the bronchioles (Fig. 3d), which expressed K5 and K14 (Fig. $3 \mathrm{e}$; data not shown). Similar results were obtained when E18.5 lungs were analyzed from embryos in which TAp63 $\alpha$ expression was induced starting at E8.5 by injecting pregnant mice daily with $100 \mu \mathrm{g} / \mathrm{kg}$ RU486 (Fig. $3 \mathrm{f}$; data not shown). In contrast, ectopic expression of $\Delta \mathrm{Np} 63 \alpha$ using the same gene-switch system did not alter lung morphology and did not result in induction of $\mathrm{K} 5$ and K14 (Fig. 3c; data not shown). Taken together, these data demonstrate that TAp $63 \alpha$, but not $\Delta \mathrm{Np} 63 \alpha$, can commit a single-layered epithelium to initiate a stratification program.

To further analyze the role of $p 63$, we used the geneswitch mice to target the overexpression of TAp63 $\alpha$ to the basal layer of the epidermis and hair follicles by using a K14 promoter (K14.Glp65; Berton et al. 2000; Cao et al. 2002). Adult (Fig. 4a-c) or newborn (data not shown) mice were treated topically once daily for $5 \mathrm{~d}$ with $100 \mu \mathrm{g}$ RU486 to induce TAp63 $\alpha$ expression. Skin biopsy specimens exhibited severe hyperplasia (Fig. 4a), and BrdU incorporation assays demonstrated that this hyperplasia was the result of hyperproliferation (Fig. 4b). In control epidermis, BrdU-labeled cells were detected sporadically in the basal layer. However, induction of TAp63 $\alpha$ expression resulted in an increase in BrdU-labeled cells in the basal layer as well as the presence of BrdU-labeled cells in the suprabasal layers of the epidermis (control $4.6 \pm 2.1$ cells $/ \mathrm{mm}$ vs. TAp63 $\alpha$-induced $97.2 \pm 5.0$ cells $/ \mathrm{mm}, P<0.01$; Fig. $4 \mathrm{~b})$. In addition, induction of TAp $63 \alpha$ expression in the epidermis resulted in
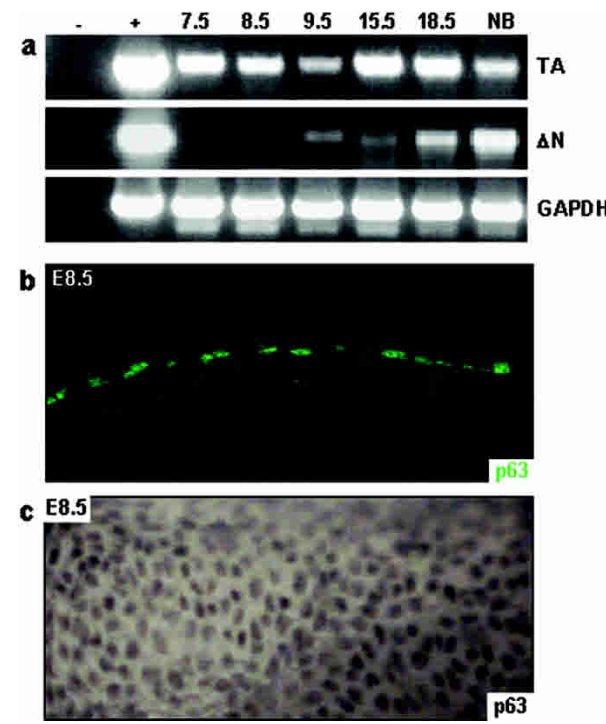

Figure 2. Differential expression of p63 isoforms occurs during embryonic development. RT-PCR analysis using primers specific for TA- or $\Delta \mathrm{Np} 63$ demonstrated that TAp63 isoforms are expressed as early as E7.5, whereas $\Delta \mathrm{Np} 63$ isoforms are not expressed until E9.5 $(a)$. Immunofluorescence $(b)$ and whole-mount immunohistochemistry $(c)$ using the mAb4A4 antibody confirmed nuclear localization of TAp63 isoforms in the surface ectoderm of E8.5 embryos. 

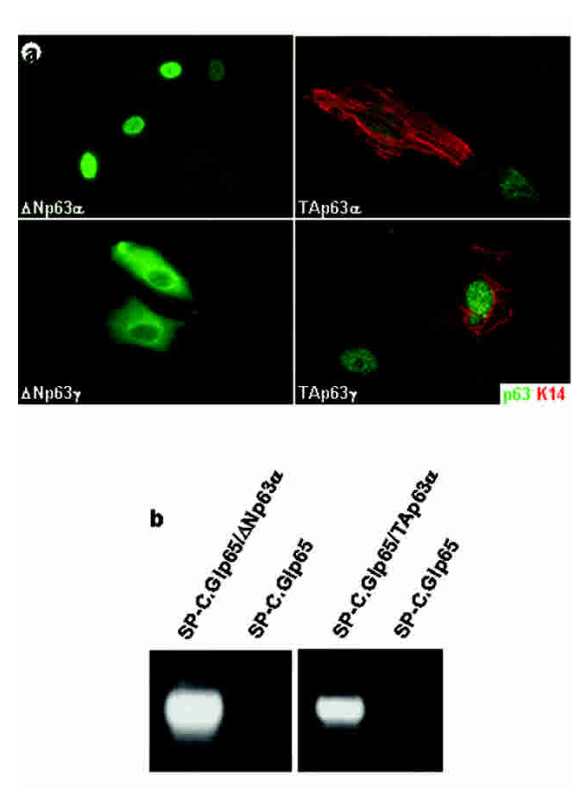

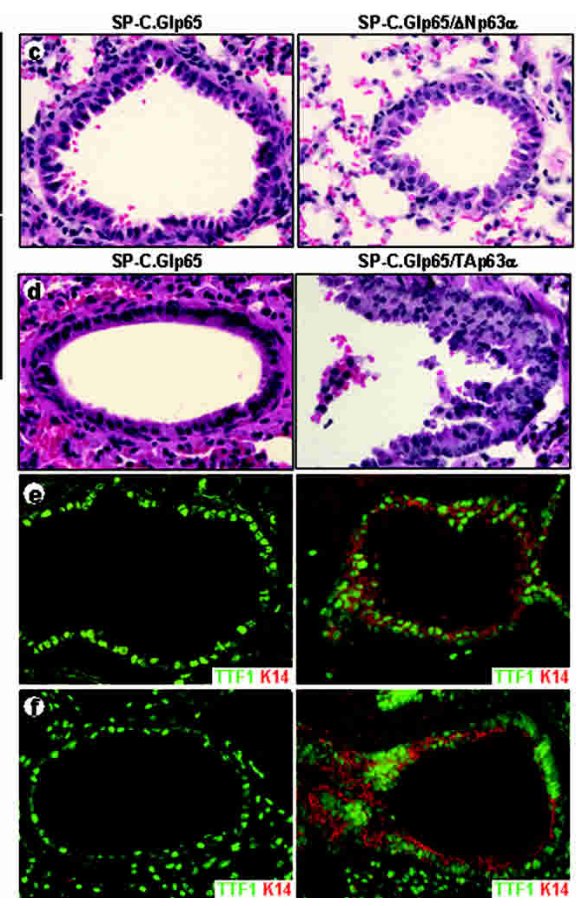

Figure 3. Ectopic expression of TAp63 $\alpha$ initiates a stratification program in vitro and in vivo. Immunofluorescence on Ptk2 cells transfected with the indicated p63 expression constructs demonstrated that only TAp63 isoforms could induce K14 expression $(-75 \%$ of the transfected cells; a). To determine if p63 could also induce a stratification program in vivo, we induced ectopic expression of TAp63 $\alpha$ or $\Delta \mathrm{Np} 63 \alpha$ in single-layered lung epithelia by using gene-switch mice. Induction of TAp63 $\alpha$ or $\Delta \mathrm{Np} 63 \alpha$ transgene expression was determined by RT-PCR $(b)$. Ectopic expression of $\Delta \mathrm{Np} 63 \alpha$ in single-layered lung epithelia did not alter lung morphology (c). Ectopic expression of TAp63 $\alpha$, however, resulted in squamous metaplastic lesions in the bronchioles $(d)$ and induction of K14 expression, a marker for stratified epithelia, in adult $(e)$ and E18.5 (f) lungs. TTF1 staining was used to identify type II alveolar cells and distal Clara cells in the bronchioles.

perturbed epidermal differentiation as demonstrated by a delayed onset of $\mathrm{K} 1$ expression (Fig. 4c), indicating an apparent failure of the basal keratinocytes to commit to terminal differentiation. We also induced TAp63 $\alpha$ expression in developing embryos starting at E8.5. Skin biopsies taken at E18.5 demonstrated that induction of
TAp $63 \alpha$ expression in embryonic epidermis, like that in newborn and adult epidermis, resulted in severe hyperplasia (Fig. 4d), hyperproliferation (data not shown), and a delayed onset of differentiation (Fig. 4e).

In an attempt to determine if TAp $63 \alpha$ expression could completely block terminal differentiation, we initiated RU486 treatment at E3.5 and analyzed the skin phenotype at E13.5. At this stage, in control embryos, the epidermis covering the fore- and hindlimbs had initiated stratification and had formed the future spinous layer, which expressed K1 (Fig. 4f). However, induction of TAp63 $\alpha$ expression in embryonic epidermis resulted in a failure to initiate stratification (Fig. 4f). To confirm that TAp $63 \alpha$ expression prevents terminal differentiation, we isolated primary keratinocytes from the epidermis of newborn K14.Glp65/TAp63 $\alpha$ mice and control mice. When primary keratinocytes are maintained in media with a low $\mathrm{Ca}^{2+}$ concentration $(0.05 \mathrm{mM})$, they proliferate and do not undergo terminal differentiation. When the $\mathrm{Ca}^{2+}$ concentration is increased $(0.1 \mathrm{mM})$, primary keratinocytes differentiate and initiate expression of $\mathrm{K} 1$ (Fig. $4 \mathrm{~g}$; Yuspa et al. 1989). However, when we induced TAp63 $\alpha$ expression in primary keratinocytes, the cells failed to differentiate after increasing the $\mathrm{Ca}^{2+}$ concentration and did not initiate $\mathrm{K} 1$ expression (Fig. 4h). In addition, it was recently demonstrated that overexpression of $\Delta \mathrm{Np} 63 \alpha$ in primary mouse keratinocytes prevents $\mathrm{Ca}^{2+}$-induced differentiation (King et al. 2003). Taken together, these findings support an additional role for p63 in maintaining keratinocytes in the proliferative compartment and in preventing their entry into terminal differentiation.
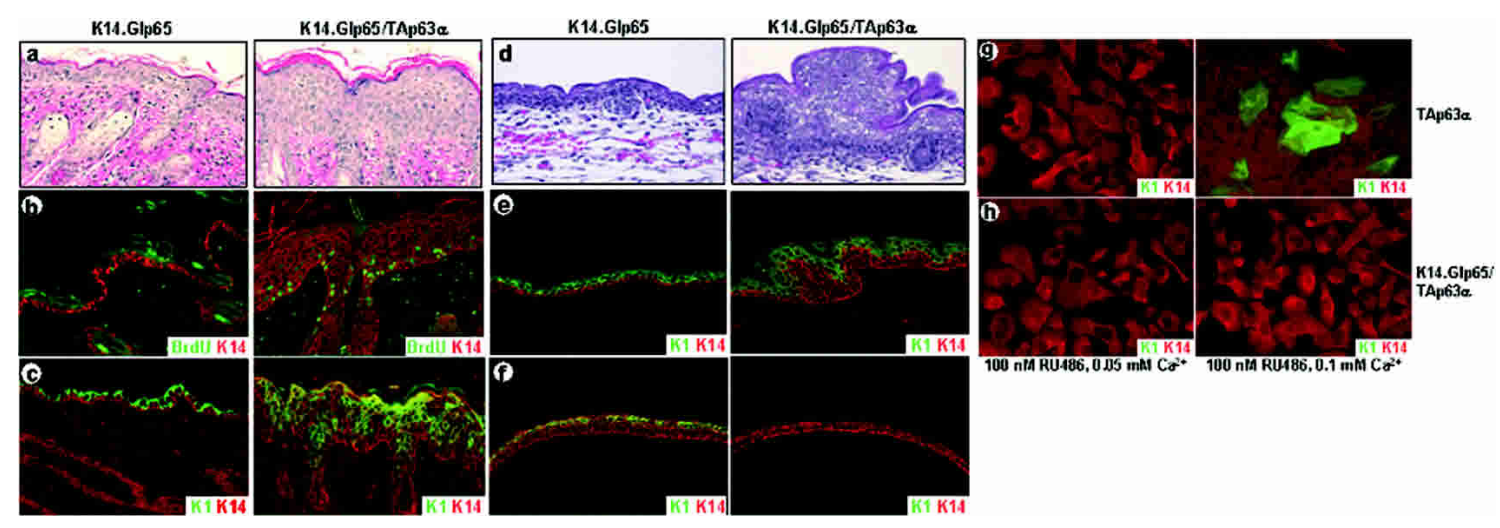

Figure 4. Induction of TAp63 $\alpha$ expression results in hyperplasia, hyperproliferation, and inhibition of terminal differentiation. Induction of TAp63 $\alpha$ expression in adult skin resulted in hyperplasia $(a)$, hyperproliferation as demonstrated by a BrdU incorporation assay $(b)$, and a delayed onset of terminal differentiation as demonstrated by a delayed onset of K1 expression $(c)$. Induction of TAp63 $\alpha$ at E8.5 resulted in hyperplasia $(d)$ and a delayed onset of $\mathrm{K} 1$ expression $(e)$ at E18.5. When TAp63 $\alpha$ expression was induced starting at E3.5, at E13.5 the developing epidermis covering the fore-and hindlimbs demonstrated a lack of $\mathrm{K} 1$ expression $(f)$. The ability of TAp63 $\alpha$ to block terminal differentiation was further demonstrated by the failure of primary keratinocytes, in which TAp63 $\alpha$ expression was induced, to undergo $\mathrm{Ca}^{2+}$-induced differentiation $(g, h)$. 
On the basis of our data, we hypothesize that one role of $\Delta \mathrm{Np} 63 \alpha$ during epidermal development is to counterbalance the effects of TAp $63 \alpha$ on terminal differentiation, thereby allowing cells to respond to terminal differentiation signals. To test whether this is true in vivo, we mated the components of the gene-switch system into the $\mathrm{p} 3^{+/-}$background, in which expression levels of all p63 isoforms are $50 \%$ of the levels in wild-type mice. Because $\Delta \mathrm{Np} 63 \alpha$ is the predominant p63 isoform expressed in the mature epidermis (Yang et al. 1998; Liefer et al. 2000), this decrease in p63 isoform expression mostly affects $\Delta \mathrm{Np} 63 \alpha$ levels. TAp $63 \alpha$ expression was induced in a $p 63^{+-}$background in newborn (Fig. 5a-d) or adult (data not shown) mice. The shift in p63 isoform expression results in a situation where TAp63 isoforms are the predominantly expressed isoforms, thereby mimicking the $p 63$ expression profile during early epidermal development. After $4 \mathrm{~d}$ of daily topical treatments with $100 \mu \mathrm{g}$ RU486, newborn K14.Glp65/ TAp $63 \alpha / p 63^{+/-}$mice appeared dehydrated and their skin exhibited cracks and peeling (Fig. 5a). Immunofluorescence analysis demonstrated that $\mathrm{K} 1$ expression was confined to the outermost layers of the epidermis where the skin was intact (Fig. 5c), and loricrin expression was completely absent (Fig. 5d). The lack of loricrin expression would impair formation of epidermal barrier function and result in water loss (Koch et al. 2000). In addition, an examination of adjacent eroded areas revealed that the epidermis was completely missing, suggesting that the marked inhibition of terminal differentiation also resulted in epidermal fragility (Fig. 5b-d). In essence, this phenotype resembles the immature embryonic skin at E14.5-E15.5, just prior to epidermal stratification. In summary, these data demonstrate that induction of TAp $63 \alpha$ in a $p 63^{+/-}$background results in an increased severity of the inhibition of terminal differentiation. Because in vitro data demonstrated that $\Delta \mathrm{Np} 63 \alpha$ has a dominant-negative function toward TAp63 $\alpha$ (Yang et al. 1998), we speculate that the switch in expression of p63 isoforms toward $\Delta \mathrm{Np} 63$ isoforms during epidermal development is required to counterbalance the inhibitory effect of TAp $63 \alpha$ on terminal differentiation.

On the basis of our data, we propose that TAp $63 \alpha$ is the molecular switch that initiates an epithelial stratification program. Execution of this program requires a shift in the balance between the p63 isoforms toward $\Delta \mathrm{Np} 63$ isoforms to allow keratinocytes to respond to signals required for maturation of the epidermis. Once the mature epidermis is formed, persistently elevated p63 levels in the basal layer of the mature epidermis are required for maintaining the proliferative potential of keratinocytes. The proliferative capacity of basal keratinocytes may be maintained through inhibition of $\mathrm{p} 21$ and 14-3-3 $\sigma$ expression via direct binding of $\Delta \mathrm{Np} 63 \alpha$ to their promoters (Westfall et al. 2003). Withdrawal from the cell cycle and commitment to terminal differentiation may be partially orchestrated by signaling through Notch and IKK $\alpha$, two molecules required for terminal differentiation of the epidermis (Hu et al. 1999; Takeda et al. 1999; Rangarajan et al. 2001; Nickoloff et al. 2002; Nicolas et al. 2003).

\section{Materials and methods}

Primary keratinocyte culture

$p 63^{-/-}$cells were isolated from the surface epithelium of E18.5 $p 63^{-/-}$ mice. Skins were floated overnight on DispaseII (Roche) at $4^{\circ} \mathrm{C}$ and pri-

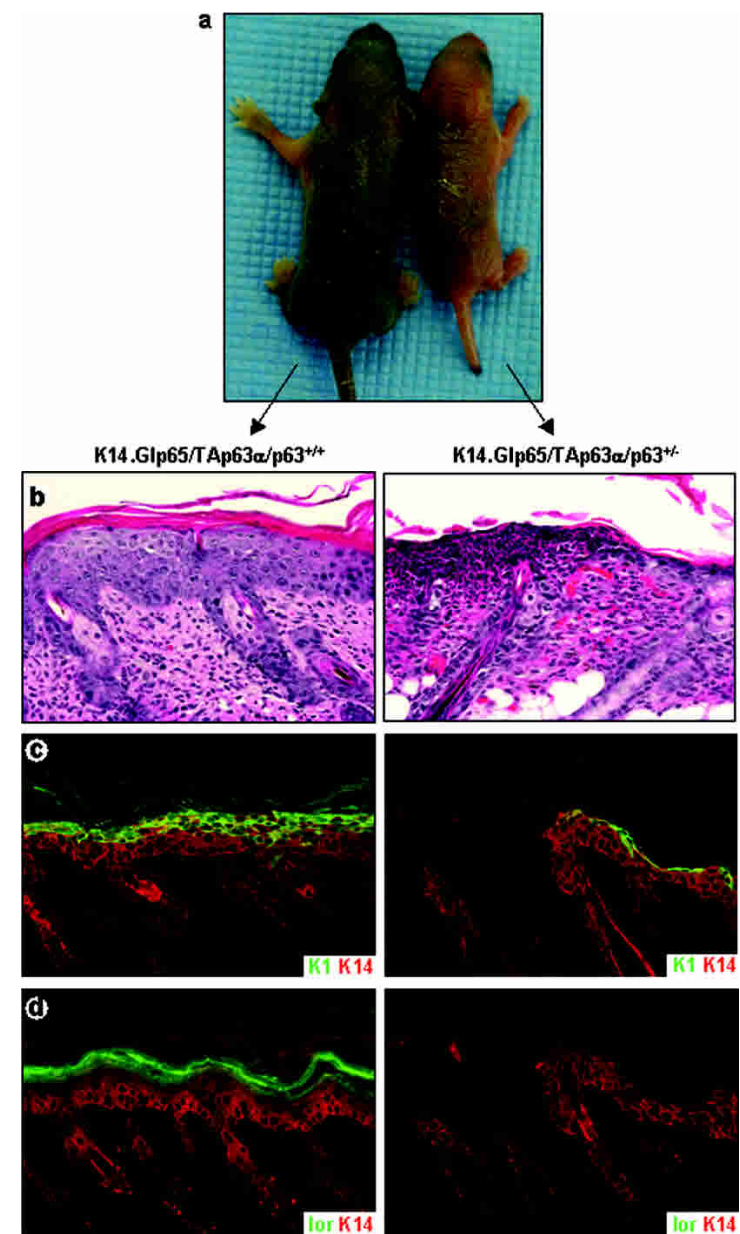

Figure 5. Induction of TAp63 $\alpha$ expression in the presence of reduced levels of $\Delta \mathrm{Np} 63 \alpha$ results in epidermal fragility. TAp63 $\alpha$ expression was induced in the epidermis of K14.Glp65/TAp63 $\alpha$ mice on a $p 63^{+/-}$or $p 63^{+/+}$genetic background. Although K14.Glp65/ TAp $63 \alpha /{\mathrm{p} 63^{+/+}}$mice looked macroscopically normal after $4 \mathrm{~d}$ of RU486 treatment, K14.Glp65/TAp63 $/ \mathrm{p} 63^{+/-}$mice developed fissures in the epidermis (a). Histologically, the lesions in K14.Glp65/ TAp $63 \alpha / p 63^{+/-}$epidermis appeared eroded $(b-d)$. In the epidermis adjacent to these lesions, $\mathrm{K} 1$ expression was confined to the outermost layers of the epidermis $(c)$, and loricrin expression was absent $(d)$, providing an explanation for the apparent fragility of the epidermis.

mary keratinocytes were isolated as described previously (Yuspa et al. 1989). Cells were cultured in 50\% fibroblast-conditioned medium supplemented with $0.05 \mathrm{mM} \mathrm{Ca}^{2+}$ and $4 \mathrm{ng} / \mathrm{mL}$ epidermal growth factor. Immunofluorescence was performed $48 \mathrm{~h}$ after plating. Cells were subcultured when the cultures reached $90 \%$ confluency.

For the in vitro differentiation assays, primary keratinocytes were isolated from the epidermis of newborn K14.Glp65/TAp63 $\alpha$ and control mice (K14.Glp65 and TAp63 $\alpha$ monogenic mice) as described previously (Yuspa et al. 1989). Transgene expression was induced by supplementing the media with $100 \mathrm{nM}$ RU486. For the differentiation assays, the $\mathrm{Ca}^{2+}$ concentration in the media was increased to $0.1 \mathrm{mM} 7 \mathrm{~d}$ after plating the cells, and cells were harvested for immunofluorescence 24 h later.

Cell lines and transfections

Cell lines that do not express p63 and K14 were identified using RT-PCR and immunofluorescence. Ptk2 cells (rat kangaroo kidney epithelial cells) were grown in supplemented EMEM medium (Cambrex Bio Science). HR9 cells (mouse embryonic endodermal cells) and F9 cells (mouse embryonic teratocarcinoma cells) were grown in supplemented DMEM medium (Invitrogen). Cells were transfected with expression constructs 
encoding myc epitope-tagged TAp63 $\alpha, \Delta \mathrm{Np} 63 \alpha$, TAp $63 \gamma$, and $\Delta \mathrm{Np} 63 \gamma$ (Yang et al. 1999) using FuGene6 (Roche). Cells were harvested for immunofluorescence $48 \mathrm{~h}$ posttransfection.

Transgenic/knockout mouse lines

To generate the inducible TAp $63 \alpha / \Delta \mathrm{Np} 63 \alpha$ transgenes, we cloned the cDNAs encoding mouse TAp $63 \alpha / \Delta \mathrm{Np} 63 \alpha$ into the UAS-TK vector or UAS-TATA vector, respectively (Wang et al. 1997). Transgenic mice were generated by standard techniques. Founder mice were identified by tail tip DNA PCR analysis using primers TK.FW (5'-GGTCGAAGCG GAGTACTGTC-3') and m63-2R (5'-GCATCGTTTCACAACCTCG-3'). K14.Glp65, SP-C.Glp65, and $p 63^{+/-}$mice were previously generated and characterized (Mills et al. 1999; Zhao et al. 2001; Cao et al. 2002).

\section{Administration of RU486 to mice}

To induce transgene expression in SP-C.Glp65/TAp63 $\alpha$ and SP-C.Glp65/ $\Delta \mathrm{Np} 63 \alpha$ mice, we injected $500 \mu \mathrm{g} / \mathrm{kg}$ RU486 (Mifepristone; Biomol), dissolved in sesame oil, i.p. once daily for 7 d. Adult or newborn K14.Glp65/ TAp $63 \alpha$ and control mice were treated topically for $5 \mathrm{~d}$ with $100 \mu \mathrm{g}$ RU486, dissolved in $70 \%$ ethanol. To induce transgene expression in utero, we injected pregnant mice daily with $100 \mu \mathrm{gg} / \mathrm{kg}$ RU486 and $0.5 \mathrm{mg}$ progesterone (to prevent potential abortion; Sigma), dissolved in sesame oil. Transgene induction in bigenic mice was confirmed by RT-PCR and RNase protection assays.

\section{In vivo BrdU incorporation and analysis}

Newborn or adult mice were injected i.p. with $250 \mu \mathrm{g} / \mathrm{g}$ BrdU (Sigma) in $0.9 \%$ sterile saline solution. Skin biopsies were taken $1 \mathrm{~h}$ later and fixed in $10 \%$ neutral buffered formalin (NBF). To determine the proliferative index, we counted four fields of cells from four independent samples and calculated the average number of BrdU positive cells per mm skin.

Immunofluorescence and whole-mount immunohistochemistry Lung tissue was fixed in $10 \%$ NBF by gravity perfusion through the cannulated trachea. Skin biopsies were fixed flat in $10 \%$ NBF. Cultured cells were fixed in cold methanol. Primary antibodies used for immunofluorescence were guinea pig anti-K14 (Yuspa et al. 1989), rabbit anti-K5 (Yuspa et al. 1989), rabbit anti-K6 (Mills et al. 1999), rabbit anti-K1 (Yuspa et al. 1989), rabbit anti-loricrin (Mills et al. 1999), mouse anti-K18 (Sigma), TTF-1 (thyroid transcription factor 1), mAb4A4 (p63; Yang et al. 1999), and FITC-conjugated anti-BrdU (Becton Dickinson). Secondary antibody conjugates used were Alexa-conjugated fluorochromes 594 goat anti-guinea pig, 488 goat anti-rabbit, 594 goat anti-rabbit, and 488 goat anti-mouse (Molecular Probes). For whole-mount immunohistochemistry, embryos were fixed in $4 \%$ paraformaldehyde. Embryos were incubated with the mAb4A4 antibody followed by biotinylated horse antimouse (Vector Laboratories) and $\mathrm{ABC}$ Elite reagent (Vector Laboratories). To detect the substrate, we incubated embryos in $\mathrm{DAB} / \mathrm{NiCl}_{2}$ followed by $\mathrm{H}_{2} \mathrm{O}_{2}$.

\section{RT-PCR analysis}

To determine the expression profile of p63 isoforms during embryogenesis, we obtained timed pregnant ICR mice from Harlan. RNA was extracted using RNeasy Kits (Qiagen) from whole embryos for stages E7.5 through E9.5 and from epidermis for stages E15.5 through newborn. Reverse transcription of $2 \mu \mathrm{g}$ of RNA was performed using random hexamers (Promega) and Moloney murine leukaemia virus reverse transcriptase (Promega). TAp63, $\triangle$ Np63, and GAPDH expression were detected by RT-PCR using primers m63TA.F (5'-TCGCAGAGCAC CCAGACA-3') and m63-2R for TAp63; m630N.F (5'-TTGTACCTG GAAAACAATG-3') and m63-2R for $\triangle$ Np63; and GAPDH1 (5'-AAGGT CGGTGTGAACGGATT-3') and GAPDH2 (5'-TGGTGGTGCAGGAT GCATTG-3') for GAPDH. To confirm transgene induction in geneswitch mice, we detected TAp $63 \alpha$ and $\Delta \mathrm{Np} 63 \alpha$ transgenes by RT-PCR using primers TK.FW and $\mathrm{m} 63-2 \mathrm{R}$.

All experiments involving mice were performed under IACUC approval (Protocol number: AN-546).

\section{Acknowledgments}

We thank Dr. Frank McKeon (Harvard Medical School, Boston, MA) for providing p63 expression constructs and the anti-p63 antibody (mAb4A4). We also thank Dr. Paolo Dotto for his constructive comments on the manuscript. This work was supported by National Institutes of Health grants HD25479 and CA52607 to D.R.R., AR47898 to D.R.R. and A.A.M., and HL61406 to F.J.D.; American Cancer Society Grant RPG95-020-04 to F.J.D.; and an award from the Centre de Recherches et d'Investigations Epidermiques et Sensorielles (CE.R.I.E.S) to D.R.R.

The publication costs of this article were defrayed in part by payment of page charges. This article must therefore be hereby marked "advertisement" in accordance with 18 USC section 1734 solely to indicate this fact.

\section{References}

Berton, T.R., Wang, X.J., Zhou, Z., Kellendonk, C., Schutz, G., Tsai, S., and Roop, D.R. 2000. Characterization of an inducible, epidermalspecific knockout system: Differential expression of lacZ in different Cre reporter mouse strains. Genesis 26: 160-161.

Byrne, C., Tainsky, M., and Fuchs, E. 1994. Programming gene expression in developing epidermis. Development 120: 2369-2383.

Cao, T., He, W., Roop, D.R., and Wang, X.J. 2002. K14-GLp65 transactivator induces transgene expression in embryonic epidermis. Genesis 32: $189-190$.

Dohn, M., Zhang, S., and Chen, X. 2001. p63alpha and DeltaNp63alpha can induce cell cycle arrest and apoptosis and differentially regulate p53 target genes. Oncogene 20: 3193-3205.

Ghioni, P., Bolognese, F., Duijf, P.H., van Bokhoven, H., Mantovani, R., and Guerrini, L. 2002. Complex transcriptional effects of p63 isoforms: Identification of novel activation and repression domains. Mol.Cell. Biol. 22: 8659-8668.

Hu, Y., Baud, V., Delhase, M., Zhang, P., Deerinck, T., Ellisman, M., Johnson, R., and Karin, M. 1999. Abnormal morphogenesis but intact IKK activation in mice lacking the IKKalpha subunit of IkappaB kinase. Science 284: 316-320.

Jackson, B.W., Grund, C., Winter, S., Franke, W.W., and Illmensee, K. 1981. Formation of cytoskeletal elements during mouse embryogenesis. II. Epithelial differentiation and intermediate-sized filaments in early postimplantation embryos. Differentiation 20: 203-216.

Kasper, M., Rudolf, T., Verhofstad, A.A., Schuh, D., and Muller, M. 1993 Heterogeneity in the immunolocalization of cytokeratin-specific monoclonal antibodies in the rat lung: Evaluation of three different alveolar epithelial cell types. Histochemistry 100: 65-71.

King, K.E., Ponnamperuma, R.M., Yamashita, T., Tokino, T., Lee, L.A., Young, M.F., and Weinberg, W.C. 2003. deltaNp63alpha functions as both a positive and a negative transcriptional regulator and blocks in vitro differentiation of murine keratinocytes. Oncogene 22: 3635 3644.

Koch, P.J., de Viragh, P.A., Scharer, E., Bundman, D., Longley, M.A., Bickenbach, J., Kawachi, Y., Suga, Y., Zhou, Z., Huber, M., et al. 2000. Lessons from loricrin-deficient mice: Compensatory mechanisms maintaining skin barrier function in the absence of a major cornified envelope protein. J. Cell Biol. 151: 389-400.

Liefer, K.M., Koster, M.I., Wang, X.J., Yang, A., McKeon, F., and Roop, D.R. 2000. Down-regulation of p63 is required for epidermal UV-Binduced apoptosis. Cancer Res. 60: 4016-4020.

Mills, A.A., Zheng, B., Wang, X.J., Vogel, H., Roop, D.R., and Bradley, A. 1999. p63 is a p53 homologue required for limb and epidermal morphogenesis. Nature 398: 708-713.

Moll, R., Franke, W.W., Schiller, D.L., Geiger, B., and Krepler, R. 1982. The catalog of human cytokeratins: Patterns of expression in normal epithelia, tumors and cultured cells. Cell 31: 11-24.

Nickoloff, B.J., Qin, J.Z., Chaturvedi, V., Denning, M.F., Bonish, B., and Miele, L. 2002. Jagged-1 mediated activation of notch signaling induces complete maturation of human keratinocytes through NF-kappaB and PPARgamma. Cell Death Differ. 9: 842-855.

Nicolas, M., Wolfer, A., Raj, K., Kummer, J.A., Mill, P., van Noort, M., Hui, C.C., Clevers, H., Dotto, G.P., and Radtke, F. 2003. Notch1 functions as a tumor suppressor in mouse skin. Nat. Genet. 33: 416421.

Pellegrini, G., Dellambra, E., Golisano, O., Martinelli, E., Fantozzi, I., Bondanza, S., Ponzin, D., McKeon, F., and De Luca, M. 2001. p63 identifies keratinocyte stem cells. Proc. Natl. Acad. Sci. 98: 3156 3161.

Rangarajan, A., Talora, C., Okuyama, R., Nicolas, M., Mammucari, C., Oh, H., Aster, J.C., Krishna, S., Metzger, D., Chambon, P., et al. 2001. 
Notch signaling is a direct determinant of keratinocyte growth arrest and entry into differentiation. $E M B O J$. 20: 3427-3436.

Takeda, K., Takeuchi, O., Tsujimura, T., Itami, S., Adachi, O., Kawai, T., Sanjo, H., Yoshikawa, K., Terada, N., and Akira, S. 1999. Limb and skin abnormalities in mice lacking IKKalpha. Science 284: 313-316.

Wang, Y., DeMayo, F.J., Tsai, S.Y., and O'Malley, B.W. 1997. Ligandinducible and liver-specific target gene expression in transgenic mice. Nat. Biotechnol. 15: 239-243.

Wang, X.J., Liefer, K.M., Tsai, S., O'Malley, B.W., and Roop, D.R. 1999. Development of gene-switch transgenic mice that inducibly express transforming growth factor betal in the epidermis. Proc. Natl. Acad. Sci. 96: 8483-8488.

Westfall, M.D., Mays, D.J., Sniezek, J.C., and Pietenpol, J.A. 2003. The Delta Np63 alpha phosphoprotein binds the p21 and 14-3-3 sigma promoters in vivo and has transcriptional repressor activity that is reduced by Hay-Wells syndrome-derived mutations. Mol. Cell Biol. 23: 2264-2276.

Wikenheiser, K.A. and Whitsett, J.A. 1997. Tumor progression and cellular differentiation of pulmonary adenocarcinomas in SV40 large T antigen transgenic mice. Am J. Respir. Cell Mol. Biol. 16: 713-723.

Wu, G., Nomoto, S., Hoque, M.O., Dracheva, T., Osada, M., Lee, C.C., Dong, S.M., Guo, Z., Benoit, N., Cohen, Y., et al. 2003. DeltaNp63alpha and TAp63alpha regulate transcription of genes with distinct biological functions in cancer and development. Cancer Res. 63: 2351-2357.

Yang, A., Kaghad, M., Wang, Y., Gillett, E., Fleming, M.D., Dotsch, V., Andrews, N.C., Caput, D., and McKeon, F. 1998. p63, a p53 homolog at 3q27-29, encodes multiple products with transactivating, deathinducing, and dominant-negative activities. Mol. Cell 2: 305-316.

Yang, A., Schweitzer, R., Sun, D., Kaghad, M., Walker, N., Bronson, R.T., Tabin, C., Sharpe, A., Caput, D., Crum, C., et al. 1999. p63 is essential for regenerative proliferation in limb, craniofacial and epithelial development. Nature 398: 714-718.

Yuspa, S.H., Kilkenny, A.E., Steinert, P.M., and Roop, D.R. 1989. Expression of murine epidermal differentiation markers is tightly regulated by restricted extracellular calcium concentrations in vitro. J. Cell Biol. 109: 1207-1217.

Zhao, B., Chua, S.S., Burcin, M.M., Reynolds, S.D., Stripp, B.R., Edwards, R.A., Finegold, M.J., Tsai, S.Y., and DeMayo, F.J. 2001. Phenotypic consequences of lung-specific inducible expression of FGF-3. Proc. Nat1. Acad. Sci. 98: 5898-5903. 


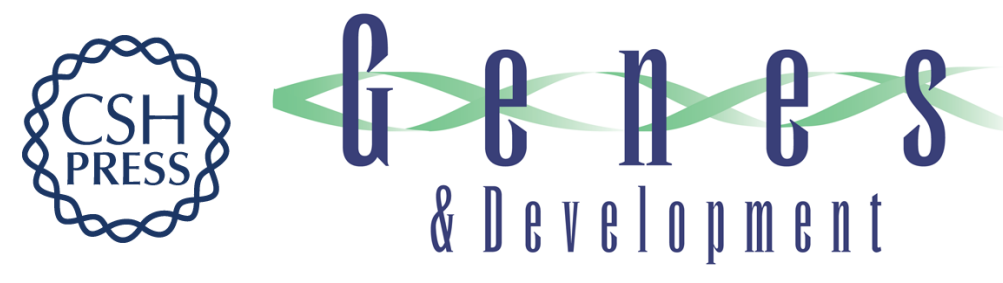

\section{p63 is the molecular switch for initiation of an epithelial stratification program}

Maranke I. Koster, Soeun Kim, Alea A. Mills, et al.

Genes Dev. 2004, 18:

Access the most recent version at doi:10.1101/gad.1165104

References This article cites 26 articles, 13 of which can be accessed free at: http://genesdev.cshlp.org/content/18/2/126.full.htmI\#ref-list-1

License

Email Alerting Receive free email alerts when new articles cite this article - sign up in the box at the top Service right corner of the article or click here.

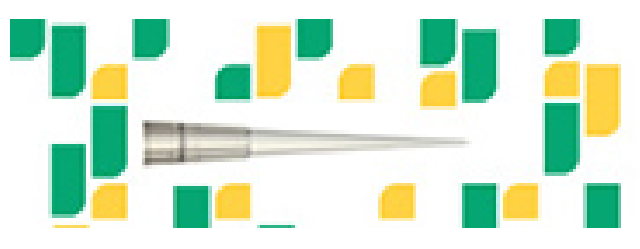

Focused on your science. 